\title{
Minor does not mean insignificant: The implications of minor complications
}

\author{
Biniam Kidane, MD, MSc, FRCSC
}

\author{
From the Section of Thoracic Surgery, Department of Surgery, Max Rady College of Medicine, University of \\ Manitoba, Winnipeg, Manitoba, Canada. \\ Disclosures: Author has nothing to disclose with regard to commercial support. \\ Received for publication Oct 5, 2017; accepted for publication Oct 7, 2017; available ahead of print Oct 31, 2017. \\ Address for reprints: Biniam Kidane, MD, MSc, FRCSC, Health Sciences Centre, GE-611, 820 Sherbrook St, \\ Winnipeg, Manitoba, Canada R3A-1R9 (E-mail: bkidane@hsc.mb.ca). \\ J Thorac Cardiovasc Surg 2018;155:808-9 \\ $0022-5223 / \$ 36.00$ \\ Copyright (C) 2017 by The American Association for Thoracic Surgery \\ https://doi.org/10.1016/j.jtcvs.2017.10.025
}

Although many studies have shown that complications are risk factors for increased hospital length of stay (LOS) after thoracic surgery, Zhang and colleagues ${ }^{1}$ point out that studies rarely focus on the impact of "minor" complications. Thus, in this issue of the Journal, the authors set out to further elucidate this. ${ }^{1}$ On this front alone, this study has scientific merit. Nevertheless, one could question whether this study adds any substantial actionable knowledge to our field. It seems fairly obvious that complications (even minor ones) are often associated with increased resource use and, by definition, increased cost. It also seems fairly obvious that we should do our best to minimize the risk of any complications. However, there is a subtle calculus of costs and benefits operating in the background that is not fairly obvious. Most centers do not do everything in their power to prevent minor complications. A hypothetical center may choose to accept a certain rate of minor "nuisance" complications if the following conditions are met: (1) The cost of that complication is thought to be low or insignificant, and (2) the cost to identify high-risk patients and prevent that complication is high. The only way to influence such calculus is to demonstrate that the cost of the complication is more significant than recognized or that the cost of preventing the complication is lower than dealing with the complication after the fact. Interpreted in this lens, this study's results take on increasing levels of relevance.

Some important issues arise when considering their results. The authors report that they had not adopted a formal Enhanced Recovery After Surgery (ERAS) program for thoracic surgery at the time of the study. The potential effect of ERAS, which has been touted to decrease LOS, on their conclusions is unclear. However, there is some debate whether formalized ERAS programs truly augment clinical and LOS outcomes in pulmonary surgery performed at high-volume thoracic centers with defined pathways., ${ }^{2,3}$ Second, the authors did not account or adjust for performance status or frailty, smoking status, or neoadjuvant status. The authors have highlighted that

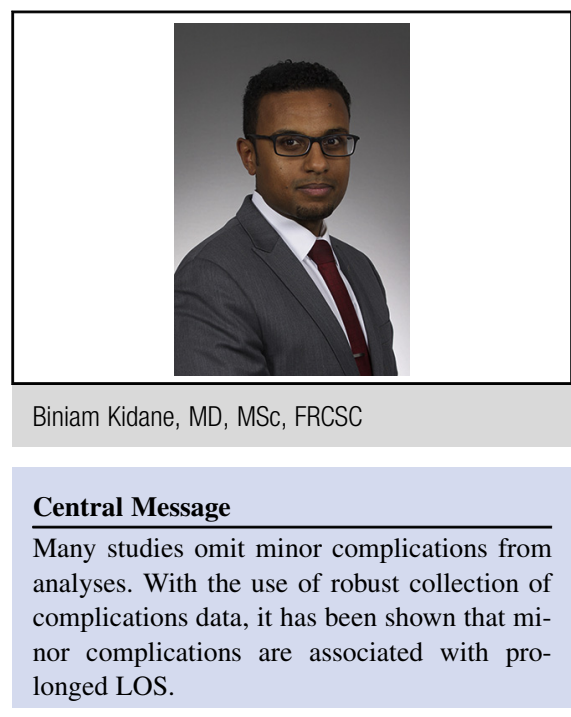

See Article page 798

even minor adverse events (AEs) are important with the underlying rationale that knowing this can potentially help us to identify high-risk individuals and implement preventative strategies. Unfortunately, the authors stopped short of elucidating the effect of some important risk features in this population. This should be the focus of future work; otherwise, the true value of this study will fall short of being realized. Last, prolonged air leak was the most common minor complication. Thus, this drives much of the reported effects. However, the authors have not investigated the impact of sending patients home with 1-way valves or portable drainage systems. This represents a potential threat to the authors' conclusions and inferences and may represent a potential way to reduce the health resource costs associated with minor complications.

Perhaps the most impressive aspect of this study is related to the procedural aspects that enhance the credibility and weight of their results. The authors have a prospective and responsive system to track $\mathrm{AE}$ data that they use for local quality-improvement work. This robust and prospective collection of granular AE data coupled with rigorous, semiprospective adjudication of AEs (ie, via weekly review) is a valuable facilitator of high-quality research. Many studies, particularly large database studies, unfortunately do not capture granular data and often result in underestimates of complications overall and specifically "minor" complications. In the end, the inescapable truth 
remains: One cannot fix what one does not see or acknowledge.

\section{References}

1. Zhang Z, Mostofian F, Ivanovic J, Gilbert S, Maziak DE, Shamji FM, et al. All grades of severity of postoperative adverse events are associated with prolonged length of stay after lung cancer resection. J Thorac Cardiovasc Surg. 2018;155: 798-807.

2. Kidane B. A rose by any other name: marginal gains of enhanced recovery after surgery in video-assisted thoracic surgery perioperative care. J Thorac Cardiovasc Surg. 2017; 154:2082-3

3. Brunelli A, Thomas C, Dinesh P, Lumb A. Enhanced recovery pathway versus standard care in patients undergoing video-assisted thoracoscopic lobectomy. $J$ Thorac Cardiovasc Surg. 2017;154:2084-90. 